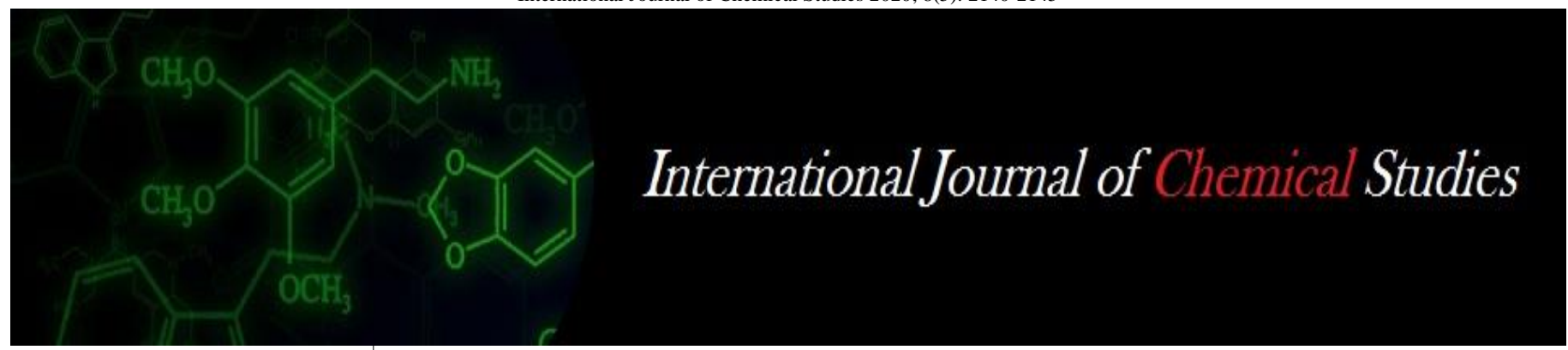

P-ISSN: 2349-8528

E-ISSN: 2321-4902

www.chemijournal.com

IJCS 2020; 8(5): 2140-2145

(C) 2020 IJCS

Received: $22-07-2020$

Accepted: 28-08-2020

\section{Priyanka Hingne}

Ph.D., Scholar, Department of

Animal Husbandry and Dairy

Science, Dr. PDKV, Akola,

Maharashtra, India

\section{SD Chavan}

Head, Department of Animal

Husbandry and Dairy Science,

Dr. PDKV, Akola, Maharashtra,

India

\section{RR Shelke}

Assistant Professor and Head of Section, AH and DS, College of Agriculture, Dr. PDKV, Akola, Maharashtra, India
Corresponding Author: Priyanka Hingne

Ph.D., Scholar, Department of Animal Husbandry and Dairy

Science, Dr. PDKV, Akola,

Maharashtra, India

\section{Sensory evaluation of herbal milk fortified with Aloe vera (Aloe barbadensis Miller) and Tulsi (Ocimum sanctum)}

\author{
Priyanka Hingne, SD Chavan and RR Shelke
}

DOI: https://doi.org/10.22271/chemi.2020.v8.i5ac.10624

\begin{abstract}
Since centuries, milk is used for making various products as well as for direct consumption. With the advent of new processing techniques, many products are added in this category. This phenomenal growth is on account of nutritional values present in milk and its acceptance as a "complete food". Flavoured milk has gained substantial popularity and is a healthy beverage targeted to children as a snack at home or school. Recently the universal trend has been a shift from synthetic to herbal medicine from centuries. Medicinal plants serve as therapeutic alternative, safer choices or in some cases for effective treatment. The present study is important for the consumers from medicinal point of view and also fulfils the daily nutritional need of herbal plants like Aloe vera and Tulsi in suitable combination with cow milk. The present study was conducted to evaluate the sensory quality of herbal flavoured milk blended with Aloe vera and Tulsi juice. In this study flavoured milk was prepared from double toned milk with $3 \%$ Tulsi juice $\left(\mathrm{T}_{1}\right)$ and 3\% Tulsi juice in combination with different levels of Aloe vera juice i.e. $2 \%\left(\mathrm{~T}_{2}\right), 4 \%$ $\left(\mathrm{T}_{3}\right), 6 \%\left(\mathrm{~T}_{4}\right), 8 \%\left(\mathrm{~T}_{5}\right)$ and $10 \%\left(\mathrm{~T}_{6}\right)$, respectively. Sugar was added @ 8 per cent of milk. The fortification of herbs improved the acceptability and sensory quality of the product. The results of sensory evaluation showed that the most acceptable quality flavoured milk could be prepared by blending $3 \%$ Tulsi juice in combination with $6 \%$ Aloe vera juice $\left(\mathrm{T}_{4}\right)$.
\end{abstract}

Keywords: Aloe vera, Tulsi, flavoured milk, sensory evaluation

\section{Introduction}

Milk is one of the important commodities among the animal products, with high nutritive value. The perfect composition of milk not only recommends itself for growing children but also suited to satisfy energy needs of adults. Plain milk is the largest consumed liquid dairy product all over the world due to its palatability, nutritious value and easy availability. If this milk is added with some ingredients like colour, flavour, sugar, this modified form is called flavoured milk and it is more acceptable by the people of all age groups from the children to adolescence. The flavoured milk is becoming an integral part of market milk industry because it has good consumer acceptance as a refreshing and nourishing milk beverage. Recently the universal trend has been a shift from synthetic to herbal medicine, which we can say 'return to nature'. Herbs have been used as food and medicine from centuries. Medicinal plants serve as therapeutic alternative, safer choices, or in some cases, for effective treatment. Ancient medicinal systems are mainly dependent on medicinal plants.

Aloe vera has a long history of use as a topical and oral therapeutic. The most widely used variety of Aloe vera is Barbadensis miller. It is one of the oldest known medicinal plants gifted by nature and hence often called' miracle plant'. Tulsi "Queen of herbs" is described as sacred and medicinal plant in ancient literature. The name Tulsi is derived from 'Sanskrit', which means "matchless one".

Milk has always been a choice of innovation for food researchers to meet the ever changing consumer's preferences for newness in the products. Many herbal plants have been an integral part of Indian culture for thousands of years and have been known for their ability to improve insomnia, increase strength, naturally regulate blood pressure and blood sugar, support weight loss, improve digestion, improve the function of our heart-lungs and is beneficial in arthritis and muscle cramping. This fact has led to an increase in consumer's interest in functional foods. 
Dairy products occupy a significant space in the functional foods market and dairy Based functional beverages are a growing segment of this sector (Vaquil and Kumar, 2017) [6,7, 17, 19].

In recent years, Aloe vera has become a subject of interest because of its beneficial effects on human health. This novel herb has anti-inflammatory, antioxidant, antimicrobial, anticancer, antidiabetic, immune boosting and hypoglycaemic properties. It regulates the peristaltic movements of intestines and promotes digestion. The liver and spleen function are stimulated by the use of this herb. Research work carried out over many years' points conclusively to a toxic colon being the cause of a very wide range of illness (Collin and Collin, 1935) ${ }^{[1]}$. Tulsi is considered to be an adaptogen, balancing different processes in the body and helpful for adapting to stress. Marked by its strong aroma and astringent taste, it is regarded in Ayurveda as a kind of "elixir of life" and believed to promote longevity. Tulsi is one of the chief sources of large number of drugs and medicine. It has very effective and remedial uses which is safe and effective, inexpensive in relation to its availability.

Nowadays, herbal foods have received high interests due to their potential nutritional safety and therapeutic effects. The interest in herbal food continues to grow, powered by progressive research efforts to identify the properties, bioactive components and potential applications and which are coupled with public interest and consumer demand and hence in view of this, the research work was planned on preparation of herbal flavoured milk blended with Aloe vera and Tulsi juice.

\section{Materials and Methods \\ 2.1 Materials}

The fresh, clean cow milk was procured from livestock instructional farm, Department of Animal Husbandry and Dairy Science, Dr. P.D.K.V., Akola. Clean crystalline commercial grade cane sugar was purchased from local market. Fresh Tulsi leaves were collected from the field of Department of Animal Husbandry and Dairy Science, Dr. P.D.K.V., Akola. Fresh Aloe vera leaves of variety (barbadensis miller) were collected from the Nagarjuna Medicinal Plants Garden, Dr. P.D.K.V., Akola.

\subsection{Methods}

\subsubsection{Preparation of Aloe vera juice}

Aloe vera juice was prepared as per procedure outlined by (Ramchandra and Rao, 2008) ${ }^{[14]}$. Fresh Aloe vera leaves were washed 3-4 times. The lower 1 inch of the leaf base, the tapering point of the leaf top 2-4 inches and the short spines located along the margins were removed. The leaf was cut into small pieces and the pulp was removed from the cuticle. The pulp was grinded so as to get homogenous juice. The juice was filtered which was then pasteurized at $85-95^{\circ} \mathrm{C}$ for 1- 2 min and then cooled at $\left(5^{\circ} \mathrm{C}\right)$.

\subsubsection{Preparation of Tulsi juice}

Fresh Tulsi leaves were collected and washed with lukewarm water. The leaves were grinded in mixer grinder and then it was filtered and Tulsi juice was obtained.

\subsubsection{Preparation of herbal flavoured milk blended Aloe vera and Tulsi juice}

The flavoured milk was prepared as per the procedure outlined by (De, 2001) with slight modification. The milk after its receipt was filtered through muslin cloth and then standardized to $1.5 \%$ fat using Pearson's square method. The standardized milk was pre-heated at $\left(60^{\circ} \mathrm{C}\right)$ and then homogenized at $(2500 \mathrm{psi})$. To the homogenized milk Aloe vera juice as per treatments, Tulsi juice, and sugar $8 \%$ was added. This mixture was blended and filtered through muslin cloth. The prepared flavoured milk was pasteurized at $71^{\circ} \mathrm{C}$ for $15 \mathrm{sec}$. The pasteurized flavoured milk was cooled at room temperature and then filled in bottles and stored at refrigeration temperature $\left(5^{\circ} \mathrm{C}\right)$.

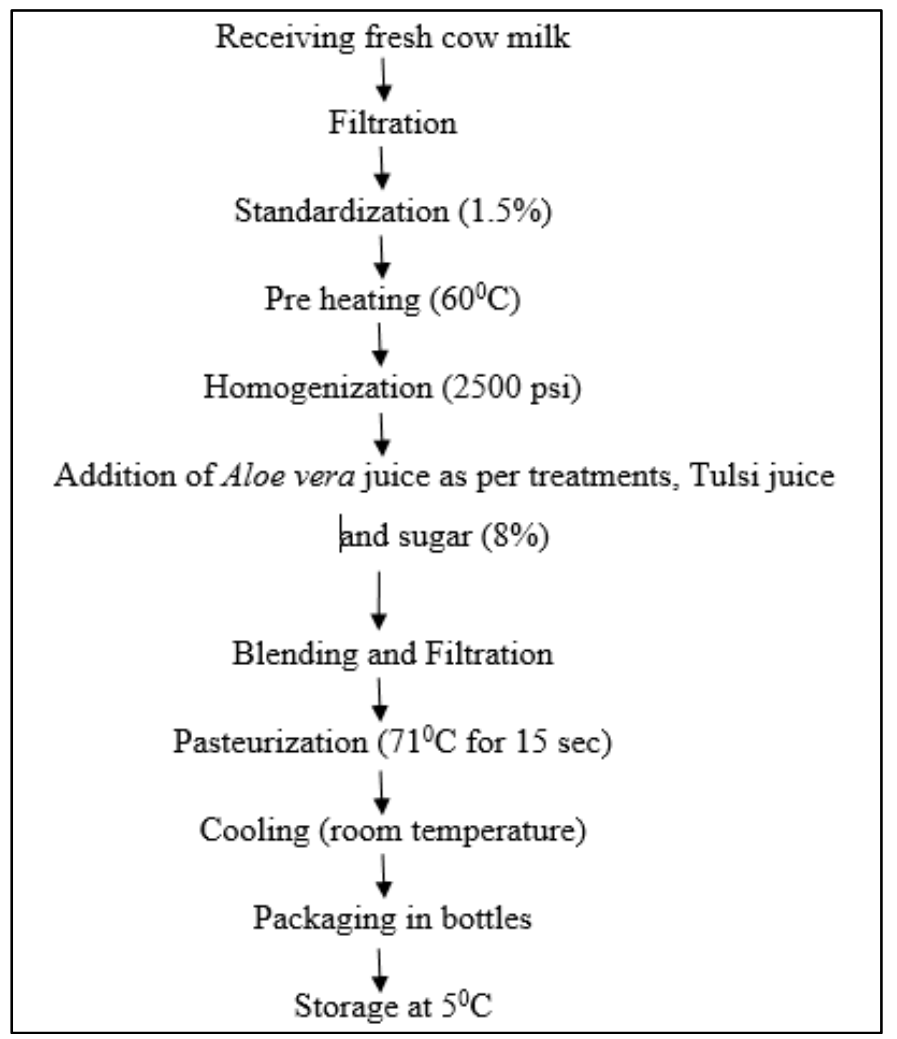

Fig 1: Flow chart of preparation of herbal flavoured milk

\section{Statistical analysis}

The data obtained in respect to sensory evaluation was statistically analyzed by completely randomized design.

\section{Results and Discussion}

Preliminary trials were first conducted to select the specific variety of Tulsi for blending. Ocimum sanctum (Rama Tulsi) was selected as the best on the basis of sensory evaluation for blending in the flavoured milk. Preliminary trials with Tulsi juice $(0,2,3,4$ and $5 \%)$ were again conducted to finalize the optimum level of Tulsi juice for blending with different levels of Aloe vera. During the preliminary trials 3\% Tulsi juice of variety Ocimum sanctum was selected as best for blending with $(0,2,4,6$ and $8 \%)$ levels of Aloe vera juice in the final experimental trials.

\subsection{Selection of Tulsi variety}

Preliminary trials were conducted using three varieties of Tulsi viz. Ocimum tenuiflorum (Krishna Tulsi), Ocimum basilicum (Sweet basil) and Ocimum sanctum (Rama Tulsi) under the treatments $A_{1}, A_{2}$ and $A_{3}$. These varieties were screened for their suitability for blending them in flavoured milk. The Tulsi juice was added @ 2\% in the milk with sugar @ 8\%. The prepared product was subjected to sensory evaluation to a panel of semi-trained judges. The data pertaining to the selection of Tulsi varieties is given in Table 1. 
Table 1: Sensory scores of flavoured milk as affected by different varieties of Tulsi

\begin{tabular}{|c|c|c|c|c|}
\hline Varieties & Flavour & Body (consistency) & Colour and appearance & Overall acceptability \\
\hline O. tenuiflorum $\left(\mathrm{A}_{1}\right)$ & 6.15 & 7.15 & 6.88 & 6.73 \\
\hline O. basilicum $\left(\mathrm{A}_{2}\right)$ & 7.10 & 7.25 & 7.23 & 7.19 \\
\hline O. sanctum $\left(\mathrm{A}_{3}\right)$ & 7.58 & 7.45 & 7.88 & 7.64 \\
\hline S.E.(m) \pm & 0.02 & 0.031 & 0.02 & 0.018 \\
\hline C.D. at 5\% & 0.071 & 0.092 & 0.080 & 0.055 \\
\hline
\end{tabular}

*Each value represents the average of four determinations

Different varieties of Tulsi significantly affected the flavour, body (consistency), colour and appearance and overall acceptability scores of the flavoured milk. The results obtained by sensory evaluation indicated that $\mathrm{A}_{3}$ i.e. Ocimum sanctum (Rama Tulsi) was highly acceptable among the other two varieties. The lowest (6.73) overall acceptability score was observed for $A_{1}$ i.e. Ocimum tenuiflorum (Krishna Tulsi) which might be due to its harsh and pungent flavour and was ranked between like slightly to like moderately. The treatment $\mathrm{A}_{2}$ i.e. Ocimum basilicum (Sweet basil) had the overall acceptability score (7.19) which was lacking the pleasant flavour as compared to Ocimum sanctum. The variety O.sanctum due its fresh, clean and pleasant flavour was superior to the other varieties and was preferred the most for blending in the flavoured milk. Similar results were found by Trivedi et al. (2014) ${ }^{[18]}$ and Husain et al. (2017) who utilized Ocimum santum in the manufacture of ice cream and herbal sandesh.
4.2 Optimization of level of Tulsi juice in the flavoured milk: During the preliminary trials, three varieties of Tulsi viz. Ocimum tenuiflorum (Krishna Tulsi), Ocimum basilicum (Sweet basil) and Ocimum sanctum (Rama Tulsi) under the treatments $A_{1}, A_{2}$ and $A_{3}$ were taken for blending in flavoured milk and were analyzed for their sensory properties. On the basis of the results obtained during the sensory evaluation, the treatment $\mathrm{A}_{3}$ i.e. flavoured milk prepared by using $O$. sanctum was preferred the most as compared to the other varieties and was selected for further study. Again for optimizing the level of Tulsi juice beaker trials were conducted to finalize the level of Tulsi juice to be added in the flavoured milk. The acceptable level was evaluated by sensory evaluation carried out under the different treatments i.e. $\mathrm{A} 3_{0}-0 \%, \mathrm{~A} 3_{2}-2 \%, \mathrm{~A}_{3}-$ $3 \%, \mathrm{~A} 34-4 \%$ and $\mathrm{A} 35-5 \%$ Tulsi juice using 9 point hedonic scale. The data pertaining to the optimization of the level of Tulsi juice in flavoured milk was analyzed and is given in Table 2.

Table 2: Effect of different levels of Tulsi juice on the sensory quality of flavoured milk

\begin{tabular}{|c|c|c|c|c|}
\hline Treatments & Flavour & Body (consistency) & Colour and appearance & Overall acceptability \\
\hline $\mathrm{A} 30$ & 7.60 & 7.75 & 7.80 & 7.71 \\
\hline $\mathrm{A} 31$ & 8.35 & 7.95 & 8.35 & 8.14 \\
\hline $\mathrm{A} 32$ & 8.60 & 8.25 & 8.40 & 8.31 \\
\hline $\mathrm{A} 33$ & 7.50 & 7.47 & 7.60 & 7.59 \\
\hline $\mathrm{A} 34$ & 7.22 & 7.25 & 7.50 & 7.37 \\
\hline S.E.(m) \pm & 0.06 & 0.13 & 0.07 & 0.09 \\
\hline C.D @ 5\% & 0.18 & 0.41 & 0.21 & 0.28 \\
\hline
\end{tabular}

*Each value represents the average of four determinations

*Treatments:

\begin{tabular}{|l|l|l|}
\hline $\mathbf{A 3}_{0}$ : 0\% Tulsi juice & A33: $2 \%$ Tulsi juice & A32: 3\% Tulsi juice \\
\hline
\end{tabular}

\begin{tabular}{l|l} 
A33: 4\% Tulsi juice & A34: 5\% Tulsi juice
\end{tabular}

The results indicate that the treatment $\mathrm{A} 33_{2}$ i.e. $3 \%$ Tulsi juice secured the highest score with respect to flavour (8.60), body (consistency) (8.25), colour and appearance (8.40) and overall acceptability (8.31). All the sensory attributes were significantly affected by the addition of different levels of Tulsi juice. The scores for flavour, body (consistency), colour and appearance and overall acceptability increased up to $3 \%$ level of Tulsi juice and thereafter declined with increase in the level of Tulsi juice. The control as well as the lower level of Tulsi juice i.e. $2 \%$ imparted almost no flavour to milk as compared to the other levels. Whereas, the higher levels of Tulsi juice i.e. $4 \%$ and $5 \%$ imparted very tinge flavour and a slight bitterness in the taste was observed. Hence, the control and the lowest level i.e. $2 \%$ as well as the highest level (4 and $5 \%$ ) were discarded by the judges during sensory evaluation and $3 \%$ Tulsi juice was considered as best for further blending with different levels of Aloe vera juice. These results are in agreement with the findings of Kumari et al. $(2011)^{[8,16]}$ who reported that the addition of Tulsi paste improved colour and appearance, body and texture and also overall acceptability of herbal yoghurt. Similarly Kumar et al. (2013) ${ }^{[6,7,17]}$ observed the highest score of colour and appearance at $3.0 \%$ level of Tulsi extract and stated that as the level of Tulsi extract increased, the score for colour and appearance in the ice cream also decreased. Likewise, Trivedi et al. (2014) [18] reported that incorporation of basil juice in the ice cream compared to control increased flavour preferences, when added up to a level of $6.0 \%(\mathrm{w} / \mathrm{w})$ only.

\subsection{Sensory evaluation of the optimized product}

The product was evaluated for its sensory characteristics by offering a sample to the panel of judges. The samples were evaluated for flavour, body (consistency), colour and appearance and overall acceptability using 9 point hedonic scale as prescribed by Nelson and Trout (1964) ${ }^{[13]}$. On the basis of the results obtained during preliminary trials $3 \%$ Tulsi juice of variety Ocimum sanctum was selected as best for blending. For the preparation of herbal flavoured milk following treatment combinations were taken:

Table 3: Show the treatment of cow milk juice

\begin{tabular}{|c|c|c|c|}
\hline Treatments & Cow milk (\%) & Tulsi juice $(\%)$ & Aloe vera juice (\%) \\
\hline $\mathrm{T}_{1}$ & 97 & 03 & 0 \\
\hline $\mathrm{T}_{2}$ & 95 & 03 & 02 \\
\hline $\mathrm{T}_{3}$ & 93 & 03 & 04 \\
\hline $\mathrm{T}_{4}$ & 91 & 03 & 06 \\
\hline $\mathrm{T}_{5}$ & 89 & 03 & 08 \\
\hline $\mathrm{T}_{6}$ & 87 & 03 & 10 \\
\hline
\end{tabular}


The sensory characteristics selected for judging fortified flavoured milk with Aloe vera and Tulsi juice were flavour, body (consistency), colour and appearance and overall acceptability. The results obtained in this respect are presented in Table 4.

\subsubsection{Flavour}

The acceptability of any food product is influenced by its flavour inspite of good appearance and colour of the product. Moreover, flavour is the contribution of taste and smell. A reference to Table 4 indicates that the dietary treatments affected significantly the flavour of herbal flavoured milk, where the score for control with $3 \%$ Tulsi juice $\left(\mathrm{T}_{1}\right)$ was significantly lower (7.46) than that of flavoured milk with $3 \%$ Tulsi juice along with $2 \%$ Aloe vera $\left(\mathrm{T}_{2}\right), 4 \%$ Aloe vera $\left(\mathrm{T}_{3}\right)$, $6 \%$ Aloe vera $\left(\mathrm{T}_{4}\right)$. The score being $7.60,7.70$ and 7.97 , respectively. While, the score of $\mathrm{T}_{1}$ was significantly higher over $3 \%$ Tulsi juice with $8 \%$ Aloe vera $\left(\mathrm{T}_{5}\right)$ and $10 \%$ Aloe vera $\left(\mathrm{T}_{6}\right)$ treatments. Moreover, significantly highest (7.97) score was received to flavoured milk containing 3\% Tulsi + $6 \%$ Aloe vera juice $\left(\mathrm{T}_{4}\right)$ over that of all other treatments. This means the $\left(\mathrm{T}_{4}\right)$ flavoured milk was above like moderately acceptability level. The important finding was that there was significant decrease in flavour score over that of other treatments $\left(\mathrm{T}_{1}\right.$ to $\left.\mathrm{T}_{4}\right)$ as a result of increasing the level of Aloe vera concentration in flavoured milk. The score decreased to (7.40) in 3\% Tulsi $+8 \%$ Aloe vera juice $\left(\mathrm{T}_{5}\right)$ and (7.28) in $3 \%$ Tulsi $+10 \%$ Aloe vera juice $\left(\mathrm{T}_{6}\right)$ combination. The lower score at higher concentration of Aloe vera juice in flavoured milk might be due to bitterness and harsh flavour to the product.

Similar views were reported by Jothylingam and Pugazhenthi (2013) ${ }^{[5]}$ where flavoured milk prepared by incorporating $5 \%$ Aloe vera pulp was ideal and increase in the concentration to $7 \%$ decreased the flavour acceptability due to bitterness. Moreover, Shrikanth et al. (2017) observed that increased level of Aloe vera in peda beyond $10 \%$ decreased the flavour score. These observations are collaborative to the present trend on decreased flavour score due to increased level of Aloe vera in milk.

Thus the results do indicate that in general the flavoured milk blended with 2, 4 and $6 \%$ Aloe vera juice with $3 \%$ Tulsi juice was within like moderately to like very much acceptability level. The score given for flavoured milk with $3 \%$ Tulsi $+6 \%$ Aloe vera juice $\left(\mathrm{T}_{4}\right)$ was highest among all the treatments and thereby can be used in order to raise the medicinal value of flavoured milk. Gaur et al. (2019) ${ }^{[3]}$ reported inclusion of $25 \%$ Tulsi juice in herbal milk improved the acceptability score and there was decrease in flavour score beyond this level due to high flavour of Tulsi over innate flavour of milk. These observations do justify the inclusion of Tulsi juice in the present study without adverse effect on flavour of milk.

\subsubsection{Body (consistency)}

The body (consistency) of the product is an important sensory attribute next to the flavour, reflecting on the acceptability of the product. The changes in score for body (consistency) of the flavoured milk with blending of Tulsi and Aloe vera juice are presented in Table: 4

It is evident from the results that addition of $3 \%$ Tulsi $+6 \%$ Aloe vera juice $\left(\mathrm{T}_{4}\right)$ received significantly highest (7.50) and lowest in $\left(\mathrm{T}_{6}\right)$ i.e. (7.05) score for consistency of flavoured milk respectively, indicating the consistency of flavoured milk from $\mathrm{T}_{1}$ to $\mathrm{T}_{6}$ treatments were above like moderately acceptability level. Moreover, the consistency score with the addition of $2 \%\left(\mathrm{~T}_{2}\right), 4 \%\left(\mathrm{~T}_{3}\right)$ Aloe vera juice along with $3 \%$ Tulsi juice was significantly more than that of control with sole 3\% Tulsi juice $\left(\mathrm{T}_{1}\right)$, the score being (7.40), (7.45), out of 9 point hedonic scale.

However, the results did indicate that there was increase in consistency score with the increase of Aloe vera level from 2 to $6 \%$ and thereafter, there was significant decrease in score at 8 and $10 \%$ level, the score decreased from 7.50 in $\left(\mathrm{T}_{4}\right)$ to 7.13 $\left(\mathrm{T}_{5}\right)$ to $7.05\left(\mathrm{~T}_{6}\right)$. This trend appeared obvious as the increased concentration of Aloe vera juice in milk decreased the total solids content due to increased percentage of moisture, resulting watery appearance and consistency to the flavoured milk. Thus fortification of flavoured milk with $3 \%$ Tulsi $+6 \%$ Aloe vera juice appeared advantageous to impart acceptable consistency to the product. This view gets support of Mudgil et al. (2016) where they noticed decrease in the consistency acceptability score beyond $10 \%$ Aloe vera fortification in buttermilk, the score decreased from 8.1 at $10 \%$ to 7.7 and 7.6 at 15 and $20 \%$ Aloe vera juice, respectively.

\subsubsection{Colour and appearance}

Appearance and colour of the product seems to be the first character for the acceptance or rejection of the product. Colour plays an important role in aesthetic quality that later gives visual clue to flavour identification and threshold (Sawale et al. 2012) ${ }^{[15]}$. It is seen from the results given in table 4 that fortification of flavoured milk with $3 \%$ Tulsi and Aloe vera juice at different levels in combination influenced significantly the colour and appearance sensory scores. In general either single $3 \%$ Tulsi juice + Aloe vera juice in combination at different levels ( 2 to $10 \%$ ) in flavoured milk were acceptable in reference to colour and appearance as the scores ranged between 7.23 to 7.60 in 9 point hedonic scale, indicating the acceptability level above like moderately. The results reported by Kumari et al. $(2011)^{[8,16]}$ are principally supportive to present trend where they stated that yoghurt prepared with 0.2 to $0.4 \%$ Tulsi juice did not influenced on colour and appearance.

However, the acceptability preference was significantly highest (7.60) for the flavoured milk containing 3\% Tulsi juice $+6 \%$ Aloe vera juice $\left(\mathrm{T}_{4}\right)$ over rest of the treatments. While significantly lowest score (7.23) was recorded for $3 \%$ Tulsi $+10 \%$ Aloe vera juice $\left(\mathrm{T}_{6}\right)$. Moreover, there was significant decrease in acceptability level with the increase of Aloe vera level, being 7.31 in $\left(\mathrm{T}_{5}\right)$ and 7.23 in $\left(\mathrm{T}_{6}\right)$ treatments over that of all other treatments $\left(\mathrm{T}_{1}\right.$ to $\left.\mathrm{T}_{4}\right)$. Perhaps, the higher ( 8 and $10 \%$ ) level of Aloe vera juice in flavoured milk might have imparted greenish tinge to flavoured milk, resulting the probable reason for less score. The present trend of results get partial support of views expressed by Mukhekar et al. (2018) $[9,11,12]$ who opined that fortification of Aloe vera at higher level imparted greenish tinge to yoghurt which decreased the score. Moreover, Shrikanth et al. (2017) reported Aloe vera juice was colourless or very light yellow or green tinge with refractive index of 1.33. Singh et al. $(2012)^{[6,15,16]}$ observed that colour and appearance score for yoghurt with $14 \%$ Aloe vera juice remained unaffected due to transparent pale green colour of Aloe vera juice which was masked by the milk colour which do not agree with present results. 
Table 4: Effect of addition of Tulsi juice and different levels of Aloe vera juice on the sensory quality of flavoured milk

\begin{tabular}{|c|c|c|c|c|}
\hline Treatments & Flavour & Body (consistency) & Colour and appearance & Overall acceptability \\
\hline $\mathrm{T}_{1}$ & 7.46 & 7.31 & 7.41 & 7.39 \\
\hline $\mathrm{T}_{2}$ & 7.60 & 7.40 & 7.48 & 7.50 \\
\hline $\mathrm{T}_{3}$ & 7.70 & 7.45 & 7.52 & 7.55 \\
\hline $\mathrm{T}_{4}$ & 7.97 & 7.50 & 7.60 & 7.68 \\
\hline $\mathrm{T}_{5}$ & 7.40 & 7.13 & 7.31 & 7.28 \\
\hline $\mathrm{T}_{6}$ & 7.28 & 7.05 & 7.23 & 7.19 \\
\hline S.E. $(\mathrm{m}) \pm$ & 0.016 & 0.016 & 0.013 & 0.008 \\
\hline C.D @ 5\% & 0.048 & 0.048 & 0.040 & 0.023 \\
\hline
\end{tabular}

*Each value represents the average of four determinations

*Treatments

\begin{tabular}{|c|c|c|c|c|c|}
\hline jui & $\begin{array}{r}2: 3 \% \mathrm{Tu} \\
\mathrm{A} .\end{array}$ & $\begin{array}{r}\mathrm{T}_{3}: 3 \% \mathrm{Tu} \\
\mathrm{A} . \mathrm{V}\end{array}$ & $\begin{array}{r}\mathbf{T}_{4}: 3 \% \mathrm{Tu} \\
\text { A. } \\
\end{array}$ & $\begin{array}{r}\mathrm{T}_{5}: 3 \% \mathrm{~T} \\
\mathrm{~A} \\
\end{array}$ & T6: \\
\hline
\end{tabular}

\subsubsection{Overall acceptability}

The overall acceptability score of flavoured milk blended with Tulsi and Aloe vera juice has been depicted in Table 4. It was observed that dietary treatment means of overall acceptability differed significantly across the treatments. Moreover, there was decrease in acceptability score with increase in Aloe vera concentration from $6 \%$ to $10 \%$ in flavoured milk. Significantly highest (7.68) and lowest (7.19) acceptability score was received to milk fortified with $6 \%\left(\mathrm{~T}_{4}\right)$ and $10 \%$ ( $\left.\mathrm{T}_{6}\right)$ Aloe vera juice. The decrease in overall acceptability score at higher concentration of Aloe vera (8 and 10\%) could be attributed to reflection of harsh flavour and watery consistency of the product.

In general, the results postulated that blending of flavoured milk with Tulsi + Aloe vera combination did not indicate any adverse effect on overall acceptability of the product as the product possessed ranking above like moderately i.e moderately good. Thus fortification of flavoured milk with $3 \%$ Tulsi $+6 \%$ Aloe vera juice can be considered optimum for the preparation of good value added product. It appears from the literature that very meager research work is available on preparation of flavoured milk blended with combination of Tulsi and Aloe vera juice. However, the research work available on the effect of blending Aloe vera juice for the preparation of other dairy products have been presented to support the present results. Kumar et al. (2015) [6, 7, 17] observed highest sensory score for overall acceptability to the beverage using 70:30 whey and Aloe vera while More et al. (2017) ${ }^{[9]}$ and Wijesundara and Adhikari (2017) ${ }^{[20]}$ reported milk shake prepared with $4 \%$ Aloe vera and drinking yoghurt with $15 \%$ Aloe vera respectively received highest overall acceptability score.

\section{Conclusion}

From the results of the present investigation it was concluded that in general, the flavoured milk fortified either with $3 \%$ Tulsi juice alone or its combination with Aloe vera juice at 2 to $10 \%$ is acceptable. However, the overall acceptability level can be differed from like moderately (moderately good) to like very much (good) depending upon the level of Aloe vera juice in combination with $3 \%$ Tulsi juice. The flavoured milk prepared by blending 3\% Tulsi juice+ $6 \%$ Aloe vera juice had good overall acceptability (7.68) and was sensorily most acceptable.

\section{References}

1. Collin C, Collin C. Roentgen dermatitis treated with fresh whole leaf species of Aloe vera. American J of Roentgen. 1935; 33(3):396-397.
2. De S. Outlines of dairy technology. New Delhi, Oxford University Press, 2013, 99-100.

3. Gaur GK, Rani R, Dharaiya CN, Solanki K. Development of herbal milk using tulsi juice, ginger juice and turmeric powder. Int. J of Chemical Studies. 2019; 7(2):1150-1157.

4. Hussain SA, David J, Beig MA, Ibrahim M, Khan MA. Studies on antioxidant properties of free fatty acid of herbal sandesh prepared with Ashwagandha (Withania somnifera) and Tulsi (Ocimum sanctum). Int. J Chemical studies. 2017; 5(2):73-76.

5. Jothylingam S, Pugazhenthi TR. Development of dietetic herbal flavoured milk and analysis for its physico chemical properties, Int. J Food, Agri. and Veterinary Sci. 2013; 3(1):54-57.

6. Kumar S, Rai DC, Singh D. The functional, rheological and sensory attributes of Tulsi (holy basil, Ocimum sanctum) extract based herbal ice cream. The Bioscan. 2013; 8(1):77-80.

7. Kumar S. Development, quality evaluation and shelf life studies of probiotic beverages using whey and Aloe vera juice. J Food Process Technol. 2015; 6(9):486.

8. Kumari K, Verma A, Neerubala. Preparation of low fat Tulsi flavoured Yoghurt. Food Sci. Res. J. 2011; 2(2):188-190.

9. More D, Desale RJ, Mukhekar A, More K. Microbiological and sensory evaluation of Aloe vera added custard apple (Annona squamosa L.) milkshake. Trends in Biosciences. 2017; 10(7):1517-1519.

10. Mugil D, Barak S, Darji P. Development and characterization of functional cultured buttermilk utilizing Aloe vera juice. Food Bioscience. 2016; 15:105109.

11. Mukhekar A, Desale RJ. Studies on physico-chemical properties of yoghurt fortified with Aloe vera. Multilogic in Science. 2018; 7(15):141-142.

12. Mukhekar A, Desale RJ, Bhosale S. Effect on sensory and microbial properties of yoghurt fortified with Aloe vera. The Pharma Innovation Journal. 2018; 7(10):146148.

13. Nelson JA, Trout GM. Judging dairy product. $4^{\text {th }}$ Edn. IVEA, Olsen Pub. Co.,Wilwdaukee, 1964, 357.

14. Ramachandra CT, Rao PS. Processing of Aloe vera leaf gel: a review. Am J Agril Biol Sci. 2008; 3(2):502-510.

15. Sawale PD, Patil GR, Singh RRB, Arvind K, Ghule AK. Potential application of milk and milk products as carrier for herbs and nutraceuticals. Current Topics in Nutraceutical Res. 2012; 10(2):101-110. 
16. Singh TP, Kumari S, Sethi S. Development of lassi containing Aloe vera juice and its quality characteristics. J Dairying, Foods and HS. 2012; 31(1):1-4.

17. Srikanth K, Kartikeyan S, Kumar SS. Effect of Aloe vera juice incorporation on textural and sensory characteristics of fresh peda. Asian J Dairy and Food Res. 2017; 36(2):127-131.

18. Trivedi VB, Prajapati JP, Pinto SV, Darji VB. Use of Basil (Tulsi) as a flavouring ingredient in the manufacture of Ice cream. AIJCSR. 2014; 3:43-62.

19. Vaquil, Kumar R. Milk based functional drinks: A review. The Pharma Innovation Journal. 2017; 6(12):1214.

20. Wijesundara WMAS, Adikari AMJB. Development of Aloe vera (Aloe barbadensis Miller) incorporated drinking yoghurt. Int. $\mathbf{J}$ of Scientific and Res Publications. 2017; 7(11):334-342. 